\title{
A Percepção dos Profissionais de Saúde e da Educação sobre o uso das Tecnologias de Informação e Comunicação no Acesso às Informações sobre o Crack
}

\section{The Perception of Healthcare and Education Professionals about the use of Information and Communication Technologies to Access Information about Crack}

\author{
(iD \\ Maykon Anderson Pires de Novais ${ }^{1}$ \\ Márcia Mello Costa De Liberal ${ }^{2}$ \\ Solange Aparecida Nappo ${ }^{3}$ \\ Paola Zucchi
}

\footnotetext{
'Universidade Federal do São Paulo (UNIFESP), Programa de Gestão e Informática da Saúde, São Paulo, SP, Brasil. ${ }^{2}$ Universidade Federal do São Paulo (UNIFESP), Departamento de Medicina, São Paulo, SP, Brasil. Autora correspondente: m.liberal@unifesp.br

${ }^{3}$ Universidade Federal do São Paulo (UNIFESP), Departamento de Medicina Preventiva, São Paulo, SP, Brasil.
}

Resumo: O crack é uma droga devastadora pelos efeitos que provoca. É um desafio para os profissionais da saúde que atuam na prevenção e no tratamento dos usuários, e para os professores dos ciclos básicos. O acesso à informação é uma forma eficiente para combater a droga e suas consequências. A pesquisa buscou identificar as Tecnologias de Informação e Comunicação utilizadas por esses profissionais para auxiliar no conhecimento sobre o crack e no desenvolvimento de programas de prevenção ao consumo e tratamento dos dependentes. Foram usadas metodologia qualitativa, amostra intencional por critérios e técnicas de investigação por meio de entrevistas semiestruturadas, triangulação da análise e informantes-chave. A fonte de busca de informações preferida pelos informantes-chave e profissionais foi a internet, onde se concentram as fontes de informação sobre o crack. A literatura pesquisada não reflete um escopo amplo sobre a área específica, comprometendo a capacitação e a ampliação de atuação desses profissionais.

Palavras-chave: Drogas na escola; Crack; Educação antitóxicos; Tecnologia da informação e da comunicação.

Abstract: Crack is a devastating drug due to its effects. It is a challenge for healthcare professionals who work in the prevention and treatment of users and for teachers of basic cycles. Access to information is an efficient way to fight drugs and their consequences. This paper aimed to identify the Information and Communication Technologies used by these professionals to help gain knowledge about crack and develop programs for the prevention of consumption and treatment of addicts. Qualitative methodology, intentional sample by criteria, and investigation techniques have been used through semi-structured interviews, analysis triangulation, and key informants. The preferred source of information search by key informants and professionals was the internet, where the sources of information about crack are concentrated. The researched literature does not reflect a broad scope on the specific area, which compromises the training of these professionals and the expansion of possibilities for their performance. technology.

Keywords: Drugs at school; Crack; Anti-drug education; Information and communication

Recebido em: 11/08/2019

Aprovado em: 07/06/2020 


\section{Introdução}

Um dos marcos da época em que vivemos são os problemas relacionados ao uso abusivo de substâncias psicoativas (ALMEIDA; MELLO, 2004). No Brasil, destaca-se o crack, derivado da cocaína que tem sido definido como uma droga devastadora, devido a seus efeitos físicos e sociais (HATSUKAMI; FISCHMAN, 1996; NAPPO; GALDURÓZ; NOTO, 1996; OLIVEIRA, NAPPO, 2008a; SIEGEL, 1982). De fácil acesso e baixo custo, fizeram com que a droga tomasse uma dimensão preocupante para a saúde pública (OLIVEIRA; NAPPO, 2008a; RIBEIRO et al., 2004, 2006). O século 21 se apresenta com forte uso do crack, em especial nos grandes centros urbanos (VASCONCELOS, 2012), o que se nota de forma intensa na região metropolitana de São Paulo. O efeito recompensador da droga e seu efeito de curta duração funcionam como estímulos à sua administração repetida, levando ao uso compulsivo (NAPPO; GALDURÓZ; NOTO, 1996).

É justamente essa forma compulsiva de consumo que leva o usuário de crack a sofrer uma série de danos que originam deterioração, perda de identidade, gerando um grande sofrimento psíquico, físico e social. No Brasil, o crack surgiu no final dos anos 1980, em São Paulo, e rapidamente conquistou as classes sociais mais baixas da cidade (INCIARDI, 1993). Além do preço mais "popular", o crack apresenta "vantagens" para o usuário: uma vez administrado, produz efeitos rapidamente (cerca de oito segundos); pode ser "fumado" (ato social bastante disseminado em nossa cultura, facilitando a adesão); dispensa equipamentos mais sofisticados para seu uso (OLIVEIRA; NAPPO, 2008b).

Por outro lado, seu efeito rápido leva a um padrão binge ${ }^{1}$ de consumo, fazendo com que a dependência e o uso compulsivo se instalem rapidamente (OLIVEIRA, NAPPO, 2008b). Nesse estágio, o usuário passa a correr risco para sustentar sua dependência, envolvendose em atividades ilícitas, passando a viver na marginalidade, além de desenvolver sintomas próprios da droga, como psicose, fissura, depressão e comportamento violento (DUAILIBI; RIBEIRO; LARANJEIRA, 2008). Entre as dificuldades dessas questões está a necessidade de aprimorar a capacitação dos profissionais de saúde que vão trabalhar na assistência de usuários e seus familiares (CRUZ; SILVA FILHO, 2005), assim como de professores do Ensino Fundamental e Médio, os quais têm grande papel na prevenção ao uso (FERREIRA et al., 2010).

Essa capacitação enfrenta dificuldades que vão além do conhecimento dos conceitos científicos. Os indicadores epidemiológicos demonstram que o consumo de crack vem aumentando no Brasil (CARLINI, 2005) e, em um cenário em constante movimento, a informação rápida, completa e confiável deve estar disponível e acessível a profissionais de saúde e professores, de forma que eles ajam baseados na realidade, respeitando as peculiaridades do local onde pretendem intervir. Bucher (1992), analisando a informação na qual se pautam os programas de prevenção ao uso de drogas, chama-a de "perversa" quando ela é manipulada, não verdadeira ou mesmo "importada". Ele afirma que, para a prevenção estar vinculada a uma ética não perversa, mas verídica, ela precisa se basear em informações claras e verdadeiras.

${ }^{1}$ Consumo de uma grande quantidade de droga em curto espaço de tempo. 
No século 21, as Tecnologias de Informação e Comunicação (TICs) constituem uma ferramenta importante para encontrar, difundir e aprofundar a informação científica desenvolvida em centros de excelência, que representam o mais adequado parâmetro de evidência para tomada de decisão em saúde. Em centros de excelência em pesquisa e produção de conhecimento científico têm-se grupos multiprofissionais - neste estudo, chamados de informantes-chave (ICs) - que são responsáveis pelo que se entende como informação precisa. Esse grupo, corroborado por López (1999), é considerado o Gold Standard de informação. Contudo, mesmo com essa capacidade de precisão, não flui para camadas distantes desses centros de referência em saúde. Questiona-se, portanto, como os profissionais de saúde e educação utilizam as TICs em sua formação e atualização em termos de conhecimento como uma alternativa de suporte para melhorar esse quadro, desde que sua utilização seja previamente concebida e aprimorada por profissionais da saúde e da educação, otimizando o uso da informação em ações de prevenção, tratamento e educação.

No caso da mídia eletrônica, Silva et al. (2003) analisaram o conhecimento que professores tinham a respeito das TICs, sua frequência na utilização e os tipos de aplicativos que servem de apoio à rotina praticada em sala de aula. Foi levantado que $60 \%$ dos entrevistados conheciam as TICs, porém, em relação à informática, nenhum deles tinha conhecimento avançado, concentrando-se apenas no básico. A quantidade de informação existente nos diversos canais de educação e formação torna o uso dessas ferramentas e acessos um desafio de implementação e recrutamento de conhecimento. Na área da saúde, a informática é capaz de agregar o conhecimento e as competências na utilização de tecnologias de informação e ações de assistência e educação em saúde.

Nesse cenário, surgem as TICs, que são, de forma geral, processos e artefatos que interligam a comunicação e a transferência de dados e informações. A world wide web (www) consiste em um dos recursos que popularizou a internet e a tornou acessível ao grande público. Portanto, a internet pode ser considerada um produto de Tecnologia de Informação. As TICs revolucionaram a forma como as pessoas se comunicam, buscam e oferecem informações. No universo educacional, foram implementadas como um novo método didático-pedagógico no auxílio da relação ensino-aprendizagem.

Dessa forma, este estudo teve como objetivo identificar as TICs, bem como suas formas de acesso, utilizadas por profissionais de saúde, da educação e dos ICs para obter informações acerca do crack. Foi investigada a percepção dos profissionais envolvidos na pesquisa sobre a qualidade e a eficiência desses meios de acesso e de suas principais necessidades, além de descrever as propriedades de acesso à informação observadas pelos profissionais investigados.

\section{Métodos}

Optou-se pela metodologia qualitativa, pois algumas características desse método ajudam o desenvolvimento deste artigo. São elas: o conhecimento científico como produto de uma visão construtiva-interpretativa (RUIZ CARRILLO, 2004; MADUREIRA, 2000), que consiste em uma nova maneira de encarar o mundo empírico (RUIZ CARRILLO, 2004), sendo que os dados deixam de "falar por si só". O caráter interativo do processo de produção do conhecimento consiste na relação que se estabelece entre o investigador e o objeto de estudo e é imprescindível à produção de conhecimento (MADUREIRA, 2000). Consiste em 
compreender, interpretar e descrever os sentidos e significados do fenômeno, a partir de valores, crenças, representações, hábitos, atitudes e opiniões do indivíduo ou do grupo que os detenha (MINAYO; SANCHES, 1993; NOGUEIRA-MARTINS; BÓGUS, 2004).

A abordagem qualitativa não privilegia o critério numérico e não busca uma amostra estatisticamente representativa. Por isso, em vez da aleatoriedade, decidiu-se pela seleção intencional da amostra ("purposeful or intentional sampling") (PATTON, 2002), escolhendo como participantes aqueles que vivenciaram o fenômeno social sob estudo, os denominados casos ricos em informação, buscando-se, dentro da amostra, a maior variedade possível de casos, de forma a contemplar as diferentes perspectivas do fenômeno.

Essas características metodológicas foram fundamentais para o desenvolvimento deste trabalho, pois opiniões, experiências e valores dos entrevistados foram seu substrato (PATTON, 2002). Buscou-se o entendimento por intermédio do discurso de profissionais de saúde (médicos, enfermeiros, assistentes sociais e psicoterapeutas) e professores do Ciclo Básico (Ensinos Médio e Fundamental), das fontes que eles utilizam para se informar e o conhecimento que têm sobre as tecnologias de acesso à informação. Também por meio de profissionais de renomado conhecimento específico, chamados de ICs, dos parâmetros utilizados como comparadores para qualificar as fontes de informação citadas pelos dois primeiros grupos.

Quanto à amostra, o estudo foi composto por profissionais de saúde, educação e ICs que, para este trabalho, compõem um grupo de comparação e discussão. Os participantes foram continuamente selecionados até que se atingiu o ponto de saturação teórica, quando as informações se tornaram repetidas, redundantes ou recorrentes (DUARTE, 2002; HUDELSON, 1994), as ideias transmitidas por um participante já tinham sido informadas por outros e a inclusão de novos participantes não resultou em compreensões adicionais ou pistas que pudessem indicar novas perspectivas do fenômeno (PATTON, 2002).

No caso dos ICs, a amostra foi composta com base exclusiva nos respondentes do inquérito que Ihes foi ofertado. Embora a amostra não tenha representatividade estatística, isso não significa que o processo de amostragem não tenha sido sistemático (HUDELSON, 1994), sendo definido pela adoção de técnicas especiais de amostragem (PATTON, 2002). Uma delas é a amostragem por critérios, os denominados critérios de inclusão. Vale lembrar que o fenômeno social estudado foi a identificação das fontes de consulta no universo das TICs utilizadas pelos profissionais de saúde, educação do Ciclo Básico e ICs, a formação e a atualização do conhecimento sobre o crack, além de da troca de experiências e desenvolvimento de programas de educação em saúde, os critérios foram: profissionais de saúde e educação envolvidos com o tema droga/crack, com diferentes origens: rede pública e privada; com tempo de trabalho na área há mais de dois anos e distintas idades.

Considerou-se que as realidades das redes públicas e privadas possam ser diferentes em termos de informação e a possibilidade de os profissionais mais jovens terem identificação maior com tecnologias ter levado a uma diferenciação de grupos etários. O tempo de dois anos foi uma medida de segurança no sentido de não se incluir na amostra recém-entrados na profissão. A seleção da amostra se deu por participantes na região metropolitana de São Paulo. A primeira etapa de obtenção da amostra foi a realização de entrevistas semiestruturadas com os ICs, pessoas que têm ligação direta com o fenômeno em investigação, dele tendo um conhecimento especial (DÍAZ; BARRUTI; DONCEL, 1992). O informante-chave auxiliou na compreensão prévia do fenômeno sob estudo, colocando o investigador frente a tópicos relevantes sobre o tema (HUDELSON, 1994). 
Para a identificação dos informantes-chave foi utilizada a Plataforma Lattes, do Conselho Nacional de Desenvolvimento Científico e Tecnológico (CNPq), para recrutamento de pesquisadores que pudessem ter o papel de ICs neste estudo. Para tanto, eles foram selecionados de acordo com os seguintes critérios: residente no país - com título de doutor - e com atividades de pesquisa no Brasil. Em associação a esses critérios, foram utilizadas as palavras "crack", "cocaína" e "drogas" para filtrar a seleção dos membros da comunidade do CNPq. Para o recrutamento dos profissionais de saúde e educação, foi utilizada a estratégia de elencar dois profissionais iniciais - os gatekeepers -, que passaram a indicar os demais no processo de seleção. Esses gatekeepers foram escolhidos a partir do notório conhecimento acerca da temática. Os profissionais de saúde não tiveram um critério profissional como requisito, mas os profissionais de educação deveriam ser necessariamente professores de Ciência ou Biologia, em função da participação no processo educativo.

Tabela 1 - Distribuição das áreas de formação dos informantes-chave da pesquisa

\begin{tabular}{lrr}
\hline \multicolumn{1}{c}{ Formação } & N. & \% \\
\hline Médico & 14 & $39 \%$ \\
Farmacêutico & 11 & $31 \%$ \\
Psicólogo & 6 & $17 \%$ \\
Enfermeiro & 3 & $8 \%$ \\
Outros & 2 & $6 \%$ \\
\hline Total & 36 & $100 \%$ \\
\hline \multicolumn{2}{c}{ Fonte: elaborada pelos autores. }
\end{tabular}

Pela maneira especial pela qual esses ICs foram contatados e a impossibilidade de uma entrevista presencial, como explicado anteriormente, foi enviado um grupo de perguntas abertas para que eles pudessem repassar para o investigador suas ideias, impressões e experiência em relação ao tema. Para realizar essa entrevista semiestruturada, foi desenvolvido formulário eletrônico por meio do aplicativo Docs, do Google, pelo qual foram solicitadas as seguintes informações: breve caracterização do participante com nome, e-mail, formação, atuação, gênero e instituição de trabalho. Fez-se uma entrevista semiestruturada caracterizada pela utilização das seguintes questões:

i. Onde você busca informações sobre crack para se atualizar e capacitar?

ii. Qual a razão de utilizar esse canal para busca de informações sobre o crack?

iii. Quais as facilidades que encontra nesse canal?

iv. Com os canais que usa para se capacitar, você ainda se sente defasado com as informações? Por quê?

v. Usa ferramentas de busca de informações além do quelhe é comumente disponibilizado por sua instituição? Por quê?

vi. Sente-se bem munido de recursos para se atualizar e se capacitar sobre o crack?

Na hipótese de existirem diferenças quanto ao tema da pesquisa entre os profissionais de saúde e da educação e a origem do trabalho, a pesquisa levou em conta os professores de escolas particulares, os professores de escolas públicas, os profissionais de saúde da rede particular e os profissionais de saúde da rede pública. A análise dos resultados, definida como de conteúdo, foi baseada nos procedimentos de organização e interpretação dos dados, 
conforme sugerido por Bardin (2004) e teve como instrumento facilitador, principalmente para a organização dos dados, o software NVivo (QSR, 2020).

\section{Resultados}

Os resultados serão apresentados obedecendo à seguinte ordem: informantes-chave, profissionais de educação e profissionais de saúde. As entrevistas, com 36 participantes (ICs), buscaram identificar as fontes de informação utilizadas pelos pesquisadores relevantes na área de drogas, de acordo com a avaliação do CNPq, e, consequentemente, servir como balizamento para as entrevistas ampliadas. Desses, todos estavam vinculados a instituições de ensino e pesquisa públicas e privadas, em diferentes segmentos, formados por médicos, farmacêuticos, psicólogos e enfermeiros, entre outros profissionais envolvidos nesta pesquisa.

\section{Dados gerais dos participantes}

- No caso do tema drogas, houve predominância de profissionais da área da saúde: médicos (39\%) e farmacêuticos (31\%);

- Quando perguntados sobre suas instituições de origem, a maioria dos entrevistados afirmou ser pesquisador ou professor de universidades federais distribuídas pelo Brasil;

- Das instituições citadas: 2,78\% estão na região Norte; $8,33 \%$ na região Sul; 2,78\% na região Centro-Oeste; $11,11 \%$ na região Nordeste; e 75\% na região Sudeste;

- Além disso, 14\% são particulares e $86 \%$ são públicas.

Em relação às fontes de busca para informações acerca do crack, a Tabela 2 apresenta a frequência de distribuição das citações feitas e coletadas através do instrumento de pesquisa utilizado com os informantes-chave.

Tabela 2 - Origem da busca de informações acerca do crack pelos informantes-chave

\begin{tabular}{lrr}
\hline \multicolumn{1}{c}{ Origem } & Frequência & $\%$ \\
\hline Bases de dados e artigos científicos & 26 & $55,32 \%$ \\
Cursos e congressos & 7 & $14,89 \%$ \\
Livros, revistas e jornais & 6 & $12,77 \%$ \\
Busca na internet ou Google & 5 & $10,64 \%$ \\
Google e base de dados científicos & 3 & $6,38 \%$ \\
\hline
\end{tabular}

Fonte: elaborada pelos autores.

Observa-se uma predominante frequência de buscas em bases de dados científicas ou artigos científicos (55\%) em oposição a buscas livres na internet em suas máquinas de busca por conteúdos diversos (10\%). Os eventos científicos foram mencionados, o que é associado ao perfil dos informantes-chave, formado em sua totalidade por membros da comunidade científica. A citação de livros, revistas e jornais, apesar de presente, não teve seus detalhes de origem declarados pelos entrevistados. Contudo, apresentaram regular fonte de citação acerca da temática crack, contribuindo para a formação do conhecimento. 
Com base em outros elementos encontrados no discurso dos participantes, foi possível associar que a confiança na informação se deposita nos repositórios indexados de artigos e nos eventos científicos aos quais os participantes têm acesso em seu cotidiano profissional. A questão das funcionalidades como rapidez, acesso residencial e disponibilidade on-line foram as mais recorrentes no que tange às maiores facilidades encontradas nos sítios de acesso.

Tabela 3 - Facilidades de acesso nos sítios de informação

\begin{tabular}{lrr}
\hline \multicolumn{1}{c}{ Facilidade } & Frequência & $\%$ \\
\hline Acessibilidade & 25 & $61 \%$ \\
Confiabilidade & 7 & $17 \%$ \\
Funcionalidade & 5 & $12 \%$ \\
Quantidade de artigos & 4 & $10 \%$ \\
\hline
\end{tabular}

Fonte: elaborada pelos autores.

Associado à acessibilidade (rapidez, disponibilidade e usabilidade), foram citados fatores como a grande quantidade de informação (artigos) e a confiança que os sítios oferecem ao usuário. Diferente do que se poderia supor, quesitos sobre a comodidade oferecida pelos sítios utilizados foram mais considerados no momento da escolha do que a abundância de informações (quantidade de artigos, 10\%). Pode-se observar que é primordial a esse grupo de entrevistados que a informação seja de qualidade, e eles a referem assim por estarem em vetores produzidos e alimentados pela comunidade científica. Nesse sentido, a informação é qualificada por esses pesquisadores e tem sua fidedignidade atestada pela comunidade científica.

Quando indagados sobre o fato de se sentirem defasados com a capacitação que os canais lhes ofereciam, houve uma equilibrada divisão de opinião e argumentos. Das frequências, 47,06\% afirmam positivamente à satisfação na capacitação. Já 52,94\% negaram haver defasagem na capacitação. Dentre os argumentos pró-capacitações estão a de que há um grande número de sítios confiáveis de busca e capacitação. Para o grupo que afirmou não estar defasado, as respostas foram diretas e desprovidas de justificativa mais ampla, muitas vezes resumida a apenas uma afirmação positiva. Entretanto, para os que se dizem não capacitados, o principal argumento se refere à escassez de estudos amplos e confiáveis sobre o crack.

Do universo de 36 participantes, dois consideraram que a pergunta não se aplicava, 19 afirmaram não utilizar recursos adicionais e citam os principais repositórios de informação como justificativa para a não necessidade de busca em outros sítios e meios de acesso. Quinze participantes afirmaram usar outros acessos para buscar informação e citaram a participação em congressos e eventos científicos, fóruns de discussão de especialistas na internet, jornais, revistas e televisão como fontes adicionais de troca e absorção de informação acerca do crack. Do total de entrevistados, 27,78\% afirmaram não se sentirem munidos de informação para oferecer capacitação sobre o crack, contra 72,22\% que afirmaram se sentirem munidos de informação. Daqueles que negaram estar capacitados, um conjunto de argumentos associados estava presente para justificar as negativas. Outros afirmam que faltam informações mais precisas acerca da droga e não questionam o acesso a ela, mas a produção em si. Outro argumento versa sobre a multidisciplinaridade do tema, que necessita da interação de diferentes profissionais e abordagens. 
As conclusões dos ICs revelaram que as fontes que consultam são confiáveis, de fácil acesso e atualizadas e consistem basicamente de artigos científicos de bases de dados indexadas. Portanto, com aval da comunidade científica. Ademais, foram entrevistados 30 professores do Ciclo Básico (Ensinos Fundamental e Médio) de escolas públicas (14 professores) e privadas (16 professores). Para eles, foi aplicado um formulário semiestruturado. A atuação dos professores nos extratos do Ciclo Básico foi de 33\% atuando apenas no Ensino Médio, 23\% atuando no Ensino Fundamental II e 43\% nos Ensinos Fundamental e Médio. Quando perguntados sobre a periodicidade com que abordavam o tema "drogas" com seus alunos, todos afirmaram fazê-lo quando alcançado o conteúdo específico na matriz curricular dos cursos ou quando viviam a realidade de ter algum de seus alunos exposto a essa circunstância. De forma unânime, os professores afirmaram abordar de forma esporádica o tema.

Quand o foram indagados se conheciam o crack e o que poderiam dizer sobre ele, todos os entrevistados afirmaram já ter ouvido falar sobre a droga. Contudo, deram detalhamento superficial acerca do que conheciam sobre ela. Ao afirmar que "já tinham ouvido falar sobre a droga", relataram que esse contato se deu por intermédio dos alunos ou pela mídia. Quando perguntados sobre o que sabiam sobre a droga, os participantes descreveram elementos diversos, resumidos em frequências na Tabela 4.

Tabela 4 - Frequência de conhecimento acerca do crack

\begin{tabular}{lrr}
\hline \multicolumn{1}{c}{ Conhecimento } & Frequência & \% \\
\hline Causam dependência & 16 & $33 \%$ \\
Causam danos orgânicos & 11 & $22 \%$ \\
Custo de aquisição & 7 & $14 \%$ \\
Efeitos sociais & 5 & $10 \%$ \\
Origem da droga & 4 & $8 \%$ \\
Efeito psíquico & 3 & $6 \%$ \\
Não sabe nada sobre a droga & 2 & $4 \%$ \\
Formas de uso & 1 & $2 \%$ \\
\hline
\end{tabular}

Fonte: elaborada pelos autores.

Observa-se que a maior frequência de citações se refere à capacidade de dependência dos usuários, seguido da capacidade de a droga causar danos ao organismo. Sobre a frequência, os participantes relatam a capacidade que ela tem de gerar dependência no usuário com rapidez e eficiência. Cabe destacar que a citação no conjunto de frequências acerca da dependência não foi associada a qualquer fenômeno de divulgação por parte de meio de comunicação específico.

Nesse item, os entrevistados fazem referência aos danos de saúde que a droga é capaz de causar e quase sempre os associam a uma lesão do sistema nervoso. Quanto à origem dela, há um menor número de citações nas falas dos entrevistados quando são questionados sobre o que sabem acerca do crack. Na abordagem Profissional, os entrevistados foram perguntados sobre como faziam a abordagem profissional a respeito do crack, em sala de aula. Dos respondentes, 32\% não abordam o tema com seus alunos, mesmo ele sendo previsto na matriz curricular do Ciclo Básico. 
Tabela 5 - Frequência de respostas sobre a abordagem profissional de professores do Ciclo Básico

\begin{tabular}{lrr}
\hline \multicolumn{1}{c}{ Conhecimento } & Frequência & $\%$ \\
\hline Orientações sobre a droga & 11 & $39 \%$ \\
Desenvolvimento de projetos educacionais & 4 & $14 \%$ \\
Não aborda o assunto & 9 & $32 \%$ \\
Situações reais & 2 & $7 \%$ \\
Uso de material didático & 2 & $7 \%$ \\
\hline
\end{tabular}

Fonte: elaborada pelos autores.

O tema drogas é abordado na matriz curricular do Ciclo Básico oficialmente de forma resumida e discreta, mas está presente no material didático. Entretanto, houve uma fração muito discreta de citações feitas pelos profissionais de educação ao abordar esse recurso como uma das suas ferramentas técnicas para uso no seu cotidiano profissional. Os professores do Ciclo Básico foram questionados abertamente sobre as fontes de informação que usavam para se informar e capacitar sobre crack.

A maioria da amostra (35\%) declarou utilizar a internet como ferramenta de informação, gerando uma predominância de uso dessa ferramenta como fonte de acesso à informação. Não foram detectados quais os sítios utilizados, contudo, pela descrição dos entrevistados, são usadas apenas máquinas de busca da internet. A análise quanto à idade dos participantes mostra heterogeneidade deles. Ou seja, não há uma tendência a profissionais mais jovens terem mais afinidade com a internet do que os mais velhos.

Quadro 1 - Resumo das comparações entre os grupos de estudo nos quesitos avaliados convergentes

\begin{tabular}{|c|c|c|c|}
\hline Quesito & Informantes-chave & Profissionais de Saúde & Profissionais de Educação \\
\hline $\begin{array}{l}\text { Desvantagens nos canais de comu- } \\
\text { nicação }\end{array}$ & $\begin{array}{l}\text { - Não encontram dificulda- } \\
\text { des }\end{array}$ & $\begin{array}{l}\text { - Confiabilidade na informa- } \\
\text { ção }\end{array}$ & - Confiabilidade na informação \\
\hline Onde buscam informação & $\begin{aligned} \text { - } & \text { Buscas em sites específicos } \\
& \text { (Bases de Dados) }\end{aligned}$ & $\begin{array}{l}\text { - Buscas livres na internet; } \\
\text { - Mídia em geral }\end{array}$ & - Buscas livres na internet \\
\hline Razão da busca no local principal & - Confiança e fidedignidade & - Facilidade & - Facilidade \\
\hline Facilidades de uso & $\begin{array}{l}\text { - Acessibilidade e confiabi- } \\
\text { lidade }\end{array}$ & - Acessibilidade & - Acessibilidade \\
\hline Efetividade na mídia de atualização & $\begin{array}{l}\text { - Atualizam e capacitam com } \\
\text { informação }\end{array}$ & $\begin{array}{l}\text { - Não capacitam ou provém } \\
\text { informação adequada }\end{array}$ & $\begin{array}{l}\text { - Provém parcialmente de } \\
\text { informação }\end{array}$ \\
\hline Melhor forma de capacitação & & - Cursos e palestras & - Cursos e palestras \\
\hline
\end{tabular}

Fonte: elaborado pelos autores.

\section{Discussão}

Neste artigo, foram estudados os profissionais da saúde e da educação, ambos na linha de frente do enfrentamento do consumo abusivo de drogas, em especial o crack. Observouse um predominante uso de TICs por parte desses profissionais para capacitação profissional na área de drogas. Todos os entrevistados apontaram a internet como o meio mais utilizado para obter informações sobre a droga. A rede se tornou um meio poderoso e em expansão de transporte de conteúdo e, aos poucos, está se tornando o meio de comunicação entre as pessoas por excelência (GADOTTI, 1999). 
As abordagens feitas pelos profissionais estudados serão discutidas em temas segregados, de modo a permitir uma comparação entre os profissionais de educação e saúde e os ICs. Estes foram selecionados propositalmente a partir de um conjunto de pesquisadores com notório conhecimento acerca do tema crack, com base nos indicadores de publicação e pesquisa científica. Foram considerados, para fins deste estudo, especialistas em informação em saúde, definida por Braga (2005) como toda informação relacionada com as condições de vida e morte de indivíduos e populações. Incluem-se, ainda, aquelas informações sobre comportamentos, produtos e serviços relacionados com o corpo e a saúde. Esse atributo dos ICs permitiu observar diferenças de estratégias de busca por informação em saúde em relação às do grupo de não especialistas.

Os ICs descreveram um fenômeno peculiar de acesso à informação em saúde. Para esse público, a informação referida como de boa qualidade se concentra em sítios específicos, que estão distantes de um público não tão especializado. A internet, na visão desses informantes, é um recurso que otimiza o processo pela busca da informação e torna a relação com o conhecimento atemporal. As TICs citadas pelos ICs na Tabela 2 se caracterizam por uma escolha de mídias na qual predomina o rigor científico, ou seja, as que têm validação por pares ou são oriundas de centros e bases de pesquisa científica. Os ICs apontaram que complementam seus conhecimentos em congressos científicos, demonstrando que a atualização do conhecimento é imprescindível na área da saúde. A escolha de fontes pelos professores do Ciclo Básico e pelos profissionais de saúde parece não seguir essa lógica. Os dois grupos citam a internet e a mídia em geral como principais fontes de informação. Releva-se que a citação internet pelos profissionais de saúde e pelos professores representa a livre navegação pelas páginas da web.

A rede se tornou um meio poderoso de transporte de informação e conteúdo em crescente expansão, e, aos poucos, está se tornando o meio de comunicação entre as pessoas por excelência (GADOTTI, 1999). Mesmo para os ICs, a busca por artigos científicos se dá por meio eletrônico, pela internet, tornando essa mídia um recurso de excelência para disponibilizar informação. A natureza das informações sobre saúde recuperadas na internet é extremamente heterogênea e sua origem remonta de sites (jornais, educacionais, acadêmicos, hospitais, clínicas e consultórios) a grupos de autoajuda organizados por indivíduos diagnosticados com determinada condição e, ainda, comunidades virtuais, redes sociais e fóruns de discussão, tornando sua credibilidade muitas vezes duvidosa.

No quesito reconhecimento da droga, houve uma unanimidade entre os profissionais de educação em afirmar já terem ouvido falar sobre o crack. O contato se deu por diferentes canais, mas a mídia foi a principal veiculadora de informação, independentemente de sua especificidade. Importante ressaltar que os materiais didáticos de consagrados autores do Ciclo Básico não citam o crack diretamente, mas classes de drogas nas quais ele pode ser incluso. O questionamento específico sobre o conhecimento da droga reflete o senso comum, ou seja, capacidade de dependência, custo baixo e efeitos sociais. Essas esferas são o que empiricamente se observa sobre a veiculação da droga pela mídia, seja escrita ou falada.

O estudo mostrou que o reconhecimento da droga se dá de forma similar entre profissionais de saúde e profissionais de educação. Essa constatação sugere que as fontes de informação para as duas esferas são as mesmas e isso se consolida quando analisadas as fontes de informação, que, pelas declarações de ambos os grupos, são bastante 
similares. O conhecimento da droga e seu poder de dependência foram citados inclusive por um profissional médico estrangeiro, demonstrando a perfusão do conhecimento dessa característica em âmbitos que não são ainda nichos da droga. O profissional em questão, membro do Programa Mais Médicos, do Governo Federal, é originário de Cuba e declara que o crack não é realidade em seu país, mas o conhecia de reportagens internacionais sobre o Brasil. Observou-se que os profissionais de saúde têm demanda e contato com a temática parcialmente diferentes da do profissional de educação.

Quando relatam o tema com seus pacientes, reforçam que isso se dá de maneira oportuna no contato profissional, quando questionam a possibilidade de uso de drogas e as complicações que esse contato pode oferecer à prática. O interesse sobre a droga, pelos pacientes, é baixo e essa condição se deve fundamentalmente ao nível social dos participantes. A abordagem profissional de ambos os grupos está centrada na orientação sobre a droga. Essa perspectiva parece óbvia quando se analisam os educadores, que têm por objetivo profissional básico conceder orientações preventivas e educativas aos educandos. Para o grupo de profissionais de saúde, essa abordagem se mostrou objetiva em função do nível de atendimento deles. A população deste artigo é formada basicamente por profissionais da Atenção Básica e não por especialista em drogas. Como descrito, a proposição se deu pela necessidade de verificar como o profissional, que é a "porta de entrada" de sistemas de especialidades, atua e seu conhecimento sobre crack.

Entende-se como necessário o profissional de saúde conhecer o uso de substâncias que possam influenciar a terapêutica necessária à sua consulta. A comparação desses grupos de profissionais indica que há uma fragilidade sobre como cada grupo usa seu conhecimento a favor de seus objetivos, sejam eles didáticos ou terapêuticos. Seja no âmbito da saúde ou no campo educacional, é visível a necessidade de uma abordagem multiprofissional e ampla para os usuários de drogas/crack. A formação profissional adequada é de extrema importância para a eficácia do atendimento dos usuários (SOUZA; BONILLA, 2014). A escola dispõe do universo ideal para o trabalho profilático relacionado ao uso de drogas/crack. Nela, a opção pelo debate franco, pela exposição e pela discussão de casos e possibilidades pode conferir uma medida de desuso de drogas significante e não mensurado.

Foi observado também um despreparo inicial de profissionais de saúde e educação quanto a temas como droga, em particular o crack, e com ênfase no profissional de saúde. Também não houve a intenção de mensurar as razões específicas que norteiam o uso da informação digital. Contudo, foi possível captar essa nuance no que tange à informação em saúde. A migração dos meios analógicos para os digitais podem ser uma justificativa para esse fenômeno. A ambiguidade do uso dos meios digitais está na preferência pelo uso desses canais ao mesmo tempo em que falta confiança nessas mídias. As principais características dos canais de comunicação escolhidos pelas populações do estudo foram relacionadas com a facilidade de uso: fidedignidade, pelos profissionais de saúde, e viabilidade de acesso, pelos educadores.

Para os profissionais de saúde, o quesito facilidade está associado à disponibilização quase imediata que a internet confere, em oposição a uma literatura convencional, por exemplo. Não foi mensurada essa relação, mas se acredita que ela esteja centrada no conhecimento técnico mais abrangente do profissional de saúde relacionado com a disponibilidade de informação existente na internet e na mídia. No caso dos educadores, eles relataram a facilidade no uso da tecnologia, condição dissociada de fatores como 
idade - que poderia indicar uma pré-disposição de geração no uso de tecnologias -, mas associada à complementação de informação encontrada nos recursos didáticos básicos. Esses recursos, contudo, são pouco dinâmicos, e a internet compensa a falta de dinamismo.

Podemos verificar uma divergência significativa das populações na análise dos resultados. A população de profissionais de educação se sente capacitada sobre o crack a partir dos canais de informação escolhidos. Já para a população de profissionais de saúde, essa condição é inversa. A convergência de que a informação flui mais rápida e facilmente é consensual entre as populações, contudo, a partir das declarações dadas pelas populações do estudo, não há consenso sobre o que a mídia de escolha para obtenção de capacitação oferece em ambos os casos (se capacita ou não). Em ambas as populações, há uma carência desse tipo de iniciativa, comprometendo a formação específica desses grupos. As iniciativas de educação permanente em saúde são essenciais à formação de recursos humanos capacitados e bem preparados para as tarefas específicas.

Para os profissionais de saúde, constatou-se a indisponibilidade de recursos para a busca de informação. O mesmo cenário aparece de forma equilibrada entre os educadores. Essa condição pode derivar do processo de informatização das escolas ter sido bem mais acelerado que o das instituições de saúde básica. No caso dos profissionais, seja no campo da saúde, seja no campo da educação, que não tinham respaldo de suas instituições, foi unânime que a busca com recursos próprios foi necessária, normalmente em horas excedentes, em suas residências. Sobre a necessidade e a demanda de mais informações sobre o crack, a predominância demostrou-se positiva, reforçando a conclusão acerca de quesitos anteriores. Frente a uma informação frágil, ampla ou não confiável, o profissional se sente despreparado para tratar a temática crack e se certifica de que a demanda pelo seu conhecimento é maior que o repositório que tem. Ferreira et al. (2010) identificaram que os professores, devido à falta de informação e ao receio de não terem respostas para sanar as dúvidas dos estudantes, demonstraram medo e incapacidade para lidar com a prevenção do uso de drogas, evitando o assunto em classe.

O fato de ambas as classes de profissionais utilizarem as mesmas fontes de informação, as quais foram demonstradas ao longo do texto como pobres e sem comprometimento com o embasamento científico, podem perpetuar estigmas divulgados por elas, dificultando muito a inclusão social de usuários de crack. Baseados nessa informação errônea, profissionais de saúde saíram a campo promovendo a internação involuntária ou compulsória de usuários de crack totalmente vulneráveis, deixados à própria sorte no centro da cidade (COELHO; OLIVEIRA, 2014). Esses profissionais insistem em promover discursos ultrapassados baseados na droga, os quais são divulgados pela mídia digital e impressa, configurando um usuário totalmente passivo, sem vontade própria e sem força interna para desistir do entorpecente. Dessa forma, é preciso que as informações a respeito de drogas, em especial o crack, tenham qualidade, sejam confiáveis, pautadas em alicerces cientificamente comprovados e englobem todos os componentes que interferem no consumo da droga e vão além disso.

\section{Considerações Finais}

Analisando a percepção dos profissionais de saúde e da educação investigados sobre a qualidade e a eficiência desses meios de acesso e suas principais necessidades, as TICs, apesar de serem as principais ferramentas de acesso, ainda não são capazes de saciar a necessidade 
por capacitação. Para eles, a informação a que estão expostos é frágil e não plenamente confiável quando originada de fontes sem a sistematização da internet. Ao descrever as propriedades de acesso à informação, as TICs a que comumente estão expostos são ágeis em prover informação, mas, sem crivos e sistematização, tornam-se frágeis. Indiretamente, a formação e a capacitação dos profissionais se apresentam deficitárias, o que seria esperado quando comparadas a uma população com acesso a informação digital e sistematizada.

A realização deste estudo permitiu aos pesquisadores elucubrar sobre as possibilidades de melhora no processo de capacitação para profissionais de educação e de saúde. Com base no observado pelos informantes-chave, a disponibilização maciça de bases de dados e periódicos científicos é uma alternativa salutar à disseminação do conhecimento científico e sistematizado. As populações estudadas fazem parte de uma região concentrada ao redor de centros de excelência em pesquisa e disseminação de informação. Acredita-se que a realidade de regiões mais distantes possa ser ainda mais comprometida, seja pelo simples acesso mais difícil à informação, seja pela (falta de) disponibilização de recursos de infraestrutura básicos de acesso, como a internet de alta velocidade.

Como conclusão deste artigo, podemos traçar um panorama da importância dos profissionais estudados na atenção e no cuidado com o usuário de drogas. A inexistência ou a deficitária capacitação a que são submetidos na área de drogas origina um conhecimento pobre do tema, possivelmente contribuindo para o pouco sucesso dos programas de prevenção e tratamento existentes. Por outro lado, após a identificação da forma pouco científica como a informação sobre crack/drogas é alcançada por esses profissionais, podese expandir essa dificuldade para outras áreas do conhecimento que estão à frente. Essa suposição é preocupante e nos leva a refletir sobre a distorção de conhecimento que se instala entre grupos, como o observado neste estudo entre os ICs e os profissionais de educação e de saúde estudados. Isso pode explicar a posição mundial baixa do Brasil quando se considera o ensino básico e, paradoxalmente, sua posição significativa em termos de produção científica e acadêmica.

\section{Referências}

ALMEIDA, G. W.; MELLO, R. C. Uso de novas tecnologias de informação por profissionais da área da saúde na Bahia. Revista de Administração Contemporânea, Curitiba, v. 8, n. 3, p. 9-27, 2004. DOI: https://doi.org/10.1590/S1415-65552004000300002.

BARDIN, L. Análise de conteúdo. 3. ed. Lisboa: Edições 70, 2004.

BRAGA, P. D. Política, tecnologia e informação em saúde: a utopia da emancipação. Revista de Administração Contemporânea, Curitiba, v. 9, n. 1, p. 246, 2005. DOI: https://doi.org/10.1590/S141565552005000100018.

BUCHER, R. A ética da prevenção. Psicologia: teoria e pesquisa, Brasília, v. 8, n. 3, p. 385-98, 1992. DOI: https://doi.org/10.1590/S0102-37722007000500021.

CARLINI, E. A. (coord.). Il levantamento domiciliar sobre o uso de drogas psicotrópicas no Brasil: estudo envolvendo as 108 maiores cidades do país: 2005. São Paulo: CEBRID: UNIFESP, 2006.

COELHO, I.; OLIVEIRA, M. H. B. Internação compulsória e crack: um desserviço à saúde pública. Saúde em Debate, Rio de Janeiro, v. 38, n. 101, p. 359-367, 2014. DOI: https://doi.org/10.5935/01031104.20140033. 
CRUZ, M. S.; SILVA FILHO, J. F. A formação de profissionais para a assistência de usuários de drogas e a constituição de um novo habitus de cuidado. Jornal Brasileiro de Psiquiatria, Rio de Janeiro, v. 54, n. 2, p. 120-126, 2005.

DÍAZ, A.; BARRUTI, M.; DONCEL, C. The lines of success?: a study on the nature and extent of cocaine use in Barcelona. Barcelona: Laboratori de Sociologia, 1992.

DUAILIBI, L. B.; RIBEIRO, M.; LARANJEIRA, R. Profile of cocaine and crack users in Brazil. Cadernos de Saúde Pública, Rio de Janeiro, v. 24, n. 4, p. 545-557, 2008. DOI: https://doi.org/10.1590/S0102$311 \times 2008001600007$.

DUARTE, R. Pesquisa qualitativa: reflexões sobre o trabalho de campo. Cadernos de Pesquisa, São Paulo, n. 115, p. 139-154, 2002. DOI: https://doi.org/10.1590/S0100-15742002000100005.

FERREIRA, T. C. D.; SANCHEZ, Z. V. M.; RIBEIRO, L. A.; OLIVEIRA, L. G.; NAPPO, S. A. Percepções e atitudes de professores de escolas públicas e privadas perante o tema drogas. Interface, Botucatu, v. 14, n. 34, p. 551-562, 2010. DOI: http://dx.doi.org/10.1590/S1414-32832010005000007.

GADOTTI, M. O ciberespaço da formação continuada: educação a distância com base na internet. Verbo de Minas, Juiz de Fora, v. 1, n. 2, p. 125-145, 1999.

HATSUKAMI, D. K.; FISCHMAN, M. W. Crack cocaine and cocaine hydrochloride: are the differences myth or reality? Jama, USA, v. 276, n. 19, p. 1580-1588, 1996. DOI: https://doi.org/10.1001/ jama.1996.03540190052029.

HUDELSON, P. M. Qualitative research for health programmes. Geneva: World Health Organization, 1994. Disponível em: https://apps.who.int/iris/handle/10665/62315. Acesso em: 10 set. 2020.

INCIARDI, J. A. Crack cocaine in the Americas. In: MONTEIRO, M. G.; INCIARDI, J. A. (ed.). Brazil-United States binational research. São Paulo: CEBRID, 1993. p. 63-75.

LÓPEZ, G. O método etnográfico como um paradigma científico e sua aplicação na pesquisa. Textura, Canoas, v. 1, n. 1, p. 45-50, 1999. Disponível em: http://www.periodicos.ulbra.br/index.php/ txra/article/view/660/470. Acesso em: 10 set. 2020.

MADUREIRA, A. F. A. A construção das identidades sexuais não-hegemônicas: gênero, linguagem e constituição da subjetividade. 2000. Dissertação (Mestrado em Psicologia) - Instituto de Psicologia, Universidade de Brasília, Brasília, 2000.

MINAYO, M. C. S.; SANCHES, O. Quantitativo-qualitativo: oposição ou complementaridade? Cadernos de Saúde Pública, Rio de Janeiro, v. 9, n. 3, p. 237-248, 1993. DOl: http://dx.doi.org/10.1590/S0102$311 \times 1993000300002$.

NAPPO, S. A.; GALDURÓZ, J. F. C.; NOTO, A. R. Crack use in São Paulo. Substance Use \& Misuse, New York, v. 31, n. 5, p. 565-579, 1996. DOI: https://doi.org/10.3109/10826089609045827.

NOGUEIRA-MARTINS, M. C. F.; BÓGUS, C. M. Considerações sobre a metodologia qualitativa como recurso para o estudo das ações de humanização em saúde. Saúde e Sociedade, São Paulo, v. 13, n. 3, p. 44-57, 2004. DOI: http://dx.doi.org/10.1590/S0104-12902004000300006.

OLIVEIRA, L. G.; NAPPO, S. A. Caracterização da cultura de crack na cidade de São Paulo: padrão de uso controlado. Revista de Saúde Pública, São Paulo, v. 42, n. 4, p. 664-671, 2008a. DOI: https://doi. org/10.1590/S0034-89102008005000039.

OLIVEIRA, L. G.; NAPPO, S. A. Crack na cidade de São Paulo: acessibilidade, estratégias de mercado e formas de uso. Archives of Clinical Psychiatry, São Paulo, v. 35, n. 6, p. 212-218, 2008b. DOI: https:// doi.org/10.1590/S0101-60832008000600002.

PATTON, M. Q. Designing qualitative studies. In: PATTON, M. Q. Qualitative research \& evaluation methods. 3. ed. Thousand Oaks: Sage, 2002. p. 209-258. 
QSR INTERNATIONAL. Nvivo pro. [2020]. Disponível em: https://www.osbsoftware.com.br/produto/ nvivo-pro. Acesso em: 10 set. 2020.

RIBEIRO, M.; DUNN, J.; LARANJEIRA, R.; SESSO, R. High mortality among young crack cocaine users in Brazil: a 5-year follow-up study. Addiction, Abingdon, v. 99, n. 9, p. 1133-1135, 2004.

RIBEIRO, M.; DUNN, J.; SESSO, R.; DIAS, A. C.; LARANJEIRA, R. Causes of death among crack cocaine users. Brazilian Journal of Psychiatry, São Paulo, v. 28, n. 3, p. 196-202, 2006. DOI: https://doi. org/10.1590/s1516-44462006000300010.

RUIZ CARRILLO, E. R. Lo cualitativo en la investigación y su actualidad. Psicologia para América Latina, México, n. 2, ago. 2004. Disponível em: https://cutt.ly/ffA8fwS. Acesso em: 23 ago. 2020.

SIEGEL, R. K. Cocaine smoking. Journal of Psychoactive Drugs, London, v. 14, n. 4, p. 271-359, 1982.

SILVA, A. M. C. et al. O Centro de Educação Federal do Rio Grande do Norte e as novas tecnologias de educação. In: PIONERISMO em educação a distância: a experiência do Rio Grande do Norte. Natal: CEFET, 2003. p. 111-133.

SOUZA, J. S.; BONILLA, M. H. S. A cultura digital na formação de professores. Revista Tempos e Espaços em Educação, São Cristóvão, SE, v. 7, n. 14, p. 23-34, 2014. DOI: https://doi.org/10.20952/ revtee.v0i0.3447.

VASCONCELOS, E. M. Cenário econômico, social e psicossocial no Brasil recente, e a crescente difusão do crack: balanço e perspectivas de ação. O Social em Questão, Rio de Janeiro, ano 15, n. 28, p. 149-186, 2012. 